\title{
AN IMMUNE-TYPE AGGLUTINATION OF MOUSE SPERMATOZOA BY PSEUDOMONAS MALTOPHILIA
}

\author{
ERIC B. BELL \\ Institute of Animal Genetics, Edinburgh
}

(Received 2nd November 1967)

\begin{abstract}
Summary. The behaviour of mouse spermatozoa in solutions of low electrolyte content was different from that reported for the rabbit. Mouse spermatozoa, suspended in isotonic solutions of glucose, sucrose and fructose, showed no tendency to agglutinate tail-to-tail (as occurs with rabbit spermatozoa) but became permanently immotile within 10 to $15 \mathrm{~min}$.
\end{abstract}

A species of bacterium (Pseudomonas maltophilia) was discovered which caused an intense agglutination of mouse spermatozoa resembling an antibody agglutination. A serially diluted culture of bacteria produced an agglutination reaction whose end-point was dependent on the concentration of spermatozoa used for the test. Spermatozoa became agglutinated head-to-head, tail-to-tail, and head-to-tail. The agglutination involved the bacteria themselves and not a product of their growth.

Five additional strains of $P$. maltophilia were examined. Four of these strains also caused agglutination of mouse spermatozoa, one strain did not. Three members of the genus Serratia were capable of agglutinating mouse spermatozoa and one other was not.

In addition to mouse spermatozoa, $P$. maltophilia agglutinated spermatozoa of the rabbit strongly and of the human slightly.

\section{INTRODUGTION}

The agglutination of spermatozoa has long been used as a method of detecting antibodies against spermatozoa. Metchnikoff (1900) and Weichardt (1901) in their studies on sperm agglutinins made no mention of the type of agglutination that was observed. Later it was recognized that mammalian spermatozoa will form a head-to-head agglutination in normal serum (Henle, Henle \& Chambers, 1938; Chang, 1947) and even in saline (Chang, 1947). Henle et al. (1938) separated bull sperm heads from tails and demonstrated the presence of head-specific and tail-specific antigens. They obtained specific head-to-head and tail-to-tail agglutinating heterologous antisera by immunizing rabbits respectively with head or tail fractions. Snell \& Poucher (1943) and McLaren (1964) scored only tail-to-tail agglutination in titrations of isoantiserum against mouse spermatozoa, in order to avoid the non-specific head-to-head agglutination which occurs with saline and with normal mouse 
serum. Tail-to-tail agglutination in the absence of specific antisera was not known to occur in the mouse. Smith (1949) occasionally found tail-to-tail agglutination of rabbit spermatozoa in normal human and goat serum but, in general, tail-to-tail agglutination of rabbit spermatozoa, which occurs along with head-to-head agglutination in iso-immunized rabbits (Edwards 1960), was strong evidence for antibody against rabbit spermatozoa. However, Bedford (1965) found that mature rabbit spermatozoa consistently agglutinated tail-to-tail in isotonic solutions of low electrolyte content.

It seemed of interest to report that although this same tail-to-tail agglutination in low electrolyte solutions did not occur with mouse spermatozoa, two species of bacteria were discovered which caused an intense tail-to-tail, head-tohead and head-to-tail agglutination in the mouse. The reaction was extremely difficult, if not impossible, to distinguish microscopically from an immune agglutination of mouse spermatozoa.

\section{MATERIAL AND METHODS}

Spermatozoa were suspended in one of the following media: isotonic, low electrolytic solutions of glucose, sucrose or fructose prepared with glass distilled water $(0.32$ м $)$; Ringer's solution; Sörenson's phosphate buffered saline, pH 7.2.

Mouse spermatozoa stripped from the vas deferens were collected fresh from males of the random bred $Q$ strain and suspended in the appropriate medium. Spermatozoa employed in the sperm agglutination test were collected in phosphate-buffered saline and the concentration adjusted to approximately $6 \mathrm{million} / \mathrm{ml}$. The suspension was lightly centrifuged to precipitate dead spermatozoa as well as clumps of spermatozoa that were adhering to cellular debris. As described by McLaren (1964), $0.05 \mathrm{ml}$ of this sperm suspension was added to $0.05 \mathrm{ml}$ of the serially diluted material being tested and examined microscopically for agglutination after 20 to $30 \mathrm{~min}$ at room temperature. The end-point of the reaction was determined by the standard method after criteria set down by Smith (1949).

Mouse blood was collected from the orbital anastomosis, allowed to clot, the serum drawn off and inactivated at $56^{\circ} \mathrm{C}$ for $30 \mathrm{~min}$ before use. Normal mouse serum was collected and pooled from eight young male $Q$ strain mice and sterilized by filtration through a Millipore filter $(0.45 \mu$ pore size). A female mouse which had received thirty-six intraperitoneal injections of freshly collected epididymal and vas deferens mouse spermatozoa over a period of 8 months served as a source of iso-antiserum.

Photographs of live spermatozoa were made by preparing a serial dilution of test material in buffered saline containing $2 \%$ gelatin. Immediately after the addition of spermatozoa, the reaction was transferred to a slide with a cover slip supported by vaseline. Thirty minutes later the slides were cooled to $4^{\circ} \mathrm{C}$ which 'froze' the spermatozoa in position for photographing but did not kill them as evidenced by the fact that vigorous movement returned to the spermatozoa when the slide warmed to room temperature.

Permanent slides of the agglutination reaction of mouse and rabbit spermatozoa were made by staining for $20 \mathrm{~min}$ in either Ehrlich's haematoxylin 
or eosin, which stained the spermatozoa, followed by $10 \mathrm{~min}$ in methyl green-pyronin which stained the bacteria.

A bacterial count of a nutrient broth culture of Pseudomonas maltophilia was made by counting the colonies after plating $0.1 \mathrm{ml}$ of a $10^{-6}$ and $10^{-7}$ dilution of bacteria on nutrient agar. Spermatozoa were counted in a haemocytometer.

Rabbit spermatozoa were obtained from the vas deferens of two rabbits or from a pooled semen sample collected by an artificial vagina. Human spermatozoa were obtained from a semen sample. When washed spermatozoa were used, they were centrifuged and washed twice in buffered saline.

\section{RESULTS}

\section{Mouse spermatozoa in low electrolyte solutions}

Isotonic solutions of glucose, sucrose and fructose did not promote, in mouse spermatozoa, a tail-to-tail agglutination of the kind described by Bedford (1965) for rabbit spermatozoa. These solutions proved to be unfavourable suspending fluids and practically all spermatozoa were irreversibly immotile within 10 to $15 \mathrm{~min}$. No agglutination of any type was observed. However, in Ringer's solution head-to-head agglutination was quite extensive. This nonspecific head-to-head agglutination was only very slight in $\mathrm{pH} 7.2$ phosphate buffered saline.

Agglutination of mouse spermatozoa by Pseudomonas maltophilia

Samples of mouse serum which had been assayed for sperm agglutinins and found to be negative were unintentionally left at room temperature for 3 days. When discovered all the samples were turbid and when re-assayed possessed sperm agglutination titres of $1: 128$ to $1: 512$. A sample of contaminated mouse serum was submitted for bacteriological examination and two organisms were identified-Pseudomonas pyocyanea and Pseudomonas maltophilia (Central Public Health Laboratory Ref. No. DRL 576/67). The latter organism is a contaminant of water and is occasionally found in human and animal tissues. It was studied in detail and reviewed by Hugh \& Ryschenkow (1961).

A sample of normal sterile mouse serum was inoculated with each of the organisms and incubated at $37^{\circ} \mathrm{C}$. At intervals of $1,2,4$ and 6 days samples were aseptically removed and stored at $-20^{\circ} \mathrm{C}$ until assaying. Each sample (approximately $0.4 \mathrm{ml}$ ) was centrifuged, and the supernatant diluted $1: 1$ with sterile saline before titration. Table 1 summarizes the results. After 2 days of incubation the sample infected with $P$. maltophilia showed marked agglutination, which appeared very similar to the agglutination of mouse spermatozoa by iso-antibody. $P$. pyocyanea, on the other hand, failed to agglutinate the spermatozoa. In fact the $P$. pyocyanea inoculum, by Day 4, was extremely toxic to the spermatozoa, killing them within a few minutes at a dilution of $1: 16$.

Examination of the $P$. maltophilia agglutination revealed a tail-to-tail adherence of the spermatozoa that had previously been regarded as indicative of an antibody agglutination. A photographic comparison was prepared between a two-fold serial dilution of the $P$. maltophilia infected serum and the same 
dilution of mouse spermatozoa iso-antisera. Representative photographs of the two titrations are illustrated in Plate 1. The appearance of the two reactions was so similar that the antibody agglutination pattern could not be reliably distinguished from the bacterial agglutination pattern.

TABLE 1

SPERM AGGLUTINATION TITRE* OF NORMAL MOUSE SERUM INOGULATED WITH Pseudomonas maltophilia OR Pseudomonas pyocyanea

\begin{tabular}{c|c|c|c}
\hline $\begin{array}{c}\text { Days of } \\
\text { incubation }\end{array}$ & $\begin{array}{c}\text { Normal } \\
\text { mouse serum }\end{array}$ & $P$. maltophilia & $P$. pyocyanea \\
\hline 1 & 8 & 8 & 8 \\
2 & & 128 & 8 \\
4 & & 512 & 8 \\
6 & & 128 & 8 \\
\hline
\end{tabular}

* Titres in all tables were recorded as the reciprocal of the highest dilution giving a positive reaction.

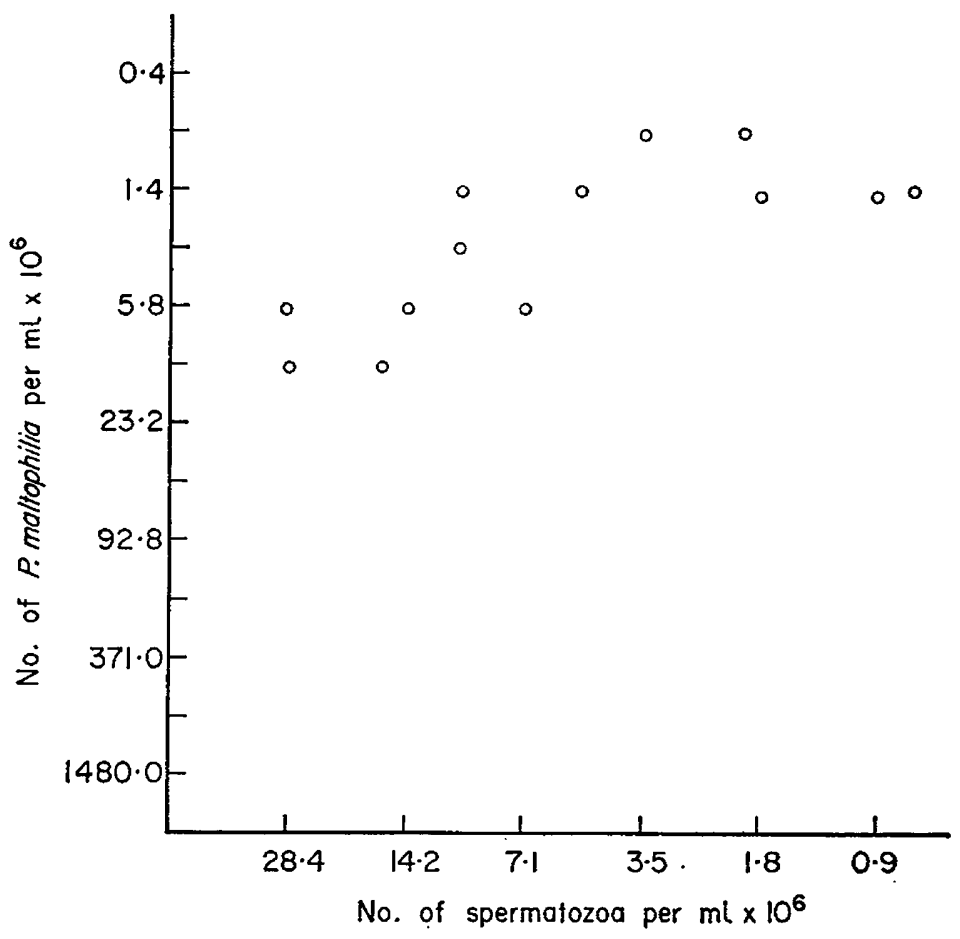

TexT-FIG. 1. Variation of the end-point $(0)$ of the sperm agglutination test on a culture of $P$. maltophilia using varying concentrations of spermatozoa.

High-power examination of the $P$. maltophilia titration revealed spermatozoa trapped in a thrashing network of struggling cells. One could observe many spermatozoa with their tails enmeshed and their heads beating vigorously. Three types of agglutination were identified: head-to-head, tail-to-tail and head-to-tail. 


\section{PLATE 1}

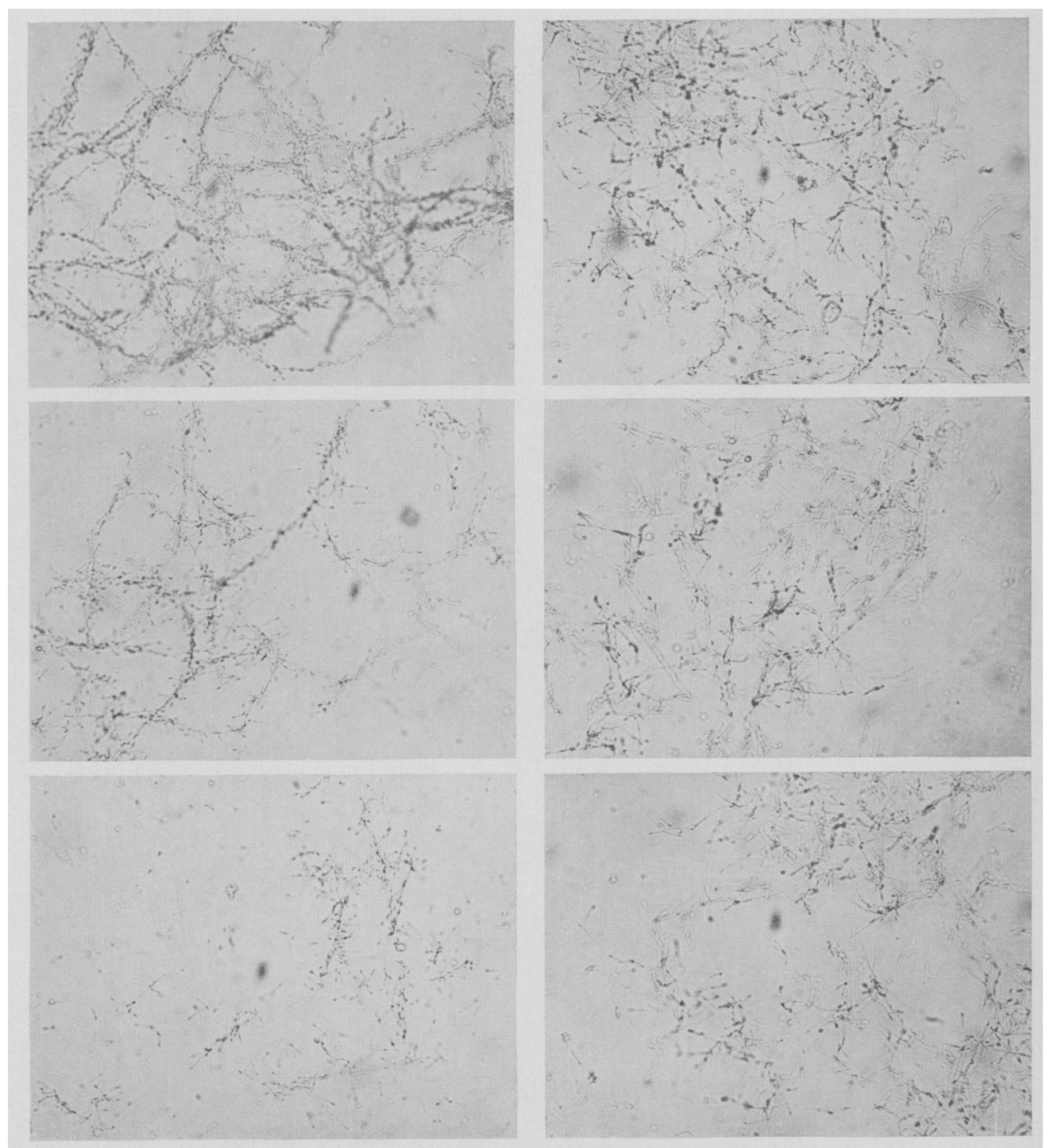

Agglutination of mouse spermatozoa by $P$. maltophilia (Column 1, left) compared with iso-antibody agglutination (Column 2, right) at representative dilutions (top to bottom:

$1: 8,1: 32,1: 128) . \times 75$. 


\section{PLATE 2}

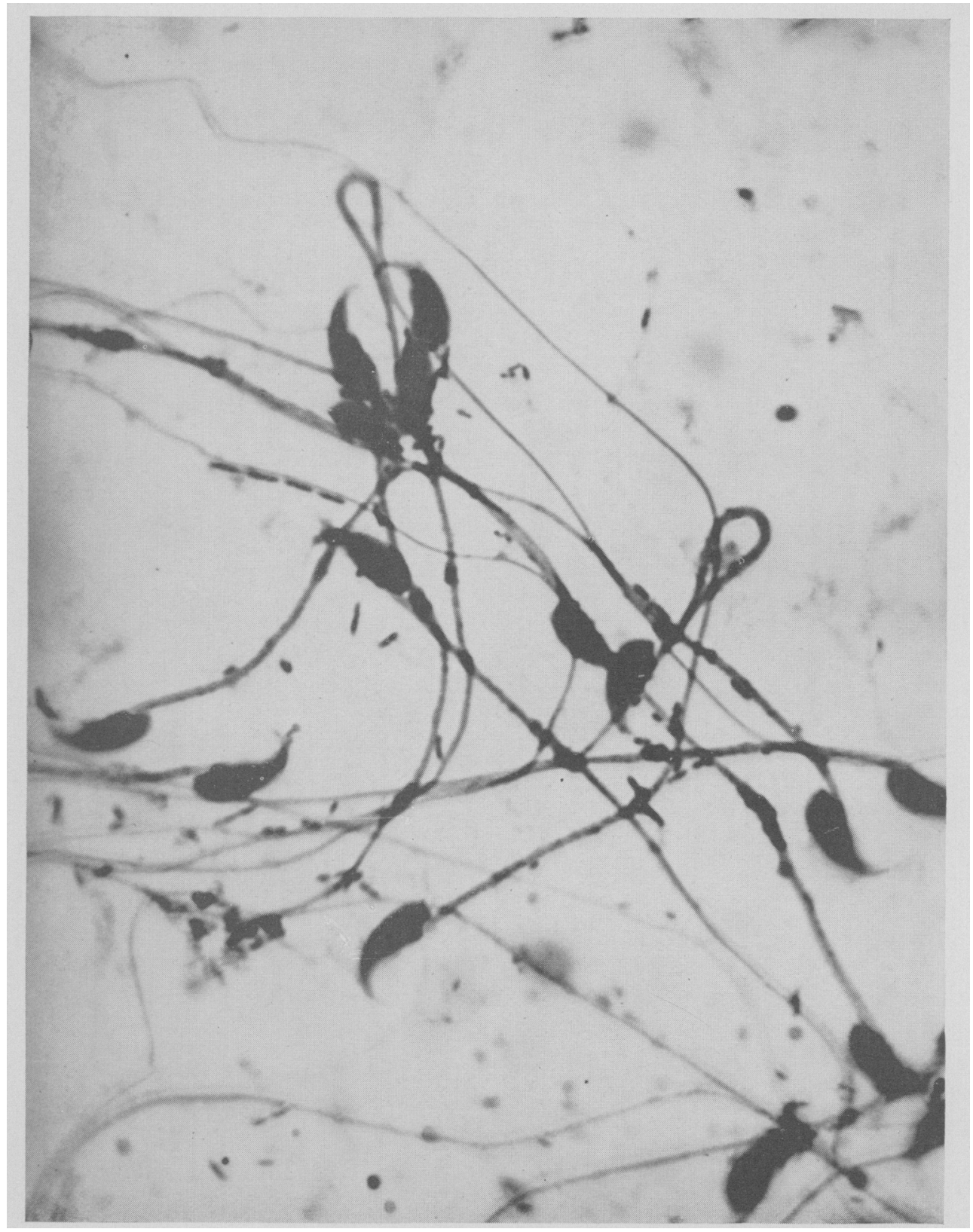

Stained preparation of mouse sperm agglutination by P. maltophilia. $\times 2000$.

(Facing p. 279) 
The mechanism involved in the $P$. maltophilia-spermatozoa reaction was investigated. Agglutination could be due either to a product of the bacterial growth or to the bacteria themselves. The reaction was abolished when the bacteria were killed by autoclaving. Filtration of $P$. maltophilia serum through a Millipore filter $(0.45 \mu$ pore size) also eliminated the agglutination. Therefore, it seemed likely that the bacteria themselves were responsible for the agglutination. If this were so, the ratio of the number of bacteria to the number of spermatozoa might affect the titre. Serially diluted quantities of a 2-day culture containing $2.97 \times 10^{9}$ live bacteria/ml were mixed with varying quantities of spermatozoa of known concentrations. The results are shown in Text-fig. 1 . As the concentration of spermatozoa decreased, the titre increased to a maximum of 1:4096 (Table 2). Suspensions of spermatozoa $\leqslant 1 \cdot 78 \times 10^{6} / \mathrm{ml}$

TABLE 2

DEGREASING QUANTITIES OF $P$. maltophilia TITRATED AGAINST VARYING QUANTITIES OF MOUSE SPERMATOZOA

\begin{tabular}{|c|c|c|c|}
\hline $\begin{array}{c}\text { No. spermatozoa } \\
(s p) / m l \times 10^{6}\end{array}$ & $\begin{array}{c}\text { No. P. maltophilia } \\
(\text { P.m. }) / m l \times 10^{6}\end{array}$ & Titre & $\begin{array}{l}\text { Ratio } \\
\text { P.m. } / s p\end{array}$ \\
\hline $\begin{array}{l}28 \cdot 4 \\
20 \cdot 6 \\
14 \cdot 2 \\
12 \cdot 8 \\
7 \cdot 10 \\
6 \cdot 40 \\
3 \cdot 55 \\
2 \cdot 28 \\
1 \cdot 78 \\
0 \cdot 89 \\
0 \cdot 88\end{array}$ & $\begin{array}{c}13.92 \text { to } 6.95^{*} \\
11 \cdot 6 \\
6.95 \\
2.90 \\
6.95 \\
1.45 \\
0.87 \\
0.73 \\
1.74 \\
1.74 \\
1.45\end{array}$ & $\begin{array}{c}250 \text { to } 500^{*} \\
256 \\
500 \\
1024 \\
500 \\
2048 \\
4000 \\
4096 \\
2000 \\
2000 \\
2048\end{array}$ & $\begin{array}{c}0.790 \text { to } 0.244 * \\
0.563 \\
0.489 \\
0.227 \\
0.978 \\
0.227 \\
0.244 \\
0.318 \\
0.977 \\
1.96 \\
1.65\end{array}$ \\
\hline
\end{tabular}

* Indicates that the end-point of the reaction was not clear.

The number of bacteria/ml was recorded at the observed end-point for a given concentration of spermatozoa.

were so thin that scoring was difficult and less accurate because the end-point had necessarily to be determined on a small amount of agglutination. Concentration of spermatozoa exceeding $28.4 \times 10^{6} / \mathrm{ml}$ could not be reliably scored because the dense overlying spermatozoa tended to obscure the agglutinated ones. However, within the range of $28.4 \times 10^{6}$ and $1.78 \times 10^{6}$ spermatozoa $/ \mathrm{ml}$, although the titre increased from 250 to 4096 , the ratio of:

$$
\text { No. of } P \text {. maltophilia }
$$

at the end-point remained within the range of 0.23 to 0.98 (Table 2).

Additional evidence that suggested the bacteria themselves were mediating the agglutination of spermatozoa came from examination of stained slides of the reaction (Plate 2). The bacilli were found adhering to the head, midpiece and tail of the mouse spermatozoa forming a 'bridge' between them and densely covering agglutinated masses of spermatozoa. 
Agglutination of mouse spermatozoa by other bacteria

In addition to the Pseudomonas maltophilia organism, another contaminating bacterium appeared which also caused the same immune-type agglutination of mouse spermatozoa. The Central Public Health Laboratory (C.P.H.L.) identified the organism as a non-pigmenting Serratia (Ref. No. DRL 575/67). At the same time five additional strains of $P$. maltophilia and three strains of Serratia (one pigmenting and two non-pigmenting), supplied by the C.P.H.L., were examined for their ability to agglutinate mouse spermatozoa. Titration of 42-hr broth cultures of these organisms (Table 3) demonstrated that four strains

TABLE 3

SPERM AGGLUTINATION TITRES OF FIVE STRAINS OF P. maltophilia AND THREE STRAINS OF Serratia

\begin{tabular}{l|l|l|l}
\hline \multicolumn{1}{c|}{ Organism } & \multicolumn{1}{c|}{ Strain } & \multicolumn{1}{c|}{$\begin{array}{c}\text { Titre of first } \\
\text { culture* }\end{array}$} & $\begin{array}{c}\text { Titre of second } \\
\text { culture* }\end{array}$ \\
\hline P. maltophilia & NCTG 10257 & 512 & 64 \\
$P$. maltophilia & $177 / 64$ & 2048 & 2048 \\
$P$. maltophilia & $374 / 65$ & Negative & Negative \\
$P$. maltophilia & $444 / 65$ & 1024 & 1024 \\
$P$. maltophilia & $338 / 67$ & $256 \dagger$ & $128 \dagger$ \\
Serratia (pigmenting) & NCTG 1377 & 2048 & 512 \\
Serratia & $687 / 66$ & $32 \dagger$ & $64 \dagger$ \\
Serratia & $1012 / 66$ & Negative & Negative \\
\hline
\end{tabular}

* All cultures contained approximately $10^{9}$ bacteria/ml. Different titres for duplicate cultures were due in part to variation in the concentrations of organisms between the first and second culture.

$\uparrow$ Agglutination patterns from these strains varied slightly from the usual pattern observed, but still resembled immune-type agglutination.

TABLE 4

AGglutination of MOUSE, RABBIT AND hUMAN SPERMATOZOA BY $P$. maltophilia

\begin{tabular}{l|c|c|ccc}
\hline \multirow{2}{*}{ Source of spermatozoa } & Spermatozoalml $\times 10^{6}$ & Titre & \multicolumn{3}{|c}{ Type of agglutination* } \\
\cline { 4 - 5 } & & & $H-H$ & $T-T$ & $H-T$ \\
\hline Mouse, epididymal & $6 \cdot 4$ & 2048 & ++ & ++ & ++ \\
Rabbit, epididymal & $14 \cdot 6$ & 1024 & +++ & + & $?$ \\
Rabbit semen & $9 \cdot 28$ & 2048 & +++ & + & $?$ \\
Rabbit, washed semen & $7 \cdot 52$ & 512 & +++ & + & $?$ \\
Human semen & $4 \cdot 72$ & $64-512$ & \pm & + & - \\
Human, washed semen & $(3 \cdot 00)$ approx. & $<64$ & & + & - \\
\hline
\end{tabular}

* Key to agglutination: +++ , intense; ++ , strong; + , weak; - , absent.

of $P$. maltophilia and two of Serratia produced immune-type sperm agglutination reactions. One strain of $P$. maltophilia and one of Serratia caused respectively no agglutination or a slight amount of head-to-head adherence. In all cases, filtration of the culture through a Millipore filter eliminated the agglutination.

Reactions of rabbit and human spermatozoa to $P$. maltophilia

Epididymal, seminal and washed seminal rabbit spermatozoa were tested in serial dilutions of $P$. maltophilia (Table 4). All gave very intense agglutination 
reactions, but differed somewhat from mouse spermatozoa in their appearance. Head-to-head adherence was the dominant pattern. Nevertheless, in low dilutions (<1:32) of $P$. maltophilia, tail-to-tail clumping was common. In higher dilutions only head-to-head agglutination occurred which was clearly distinguishable from the non-specific head-to-head adherence that occurs normally with rabbit spermatozoa.

Human spermatozoa behaved differently from either mouse or rabbit (Table 4). Although a small number of spermatozoa adhered tail-to-tail, no massive agglutination occurred. The amount of agglutination was so small that a definite end-point could not be established.

\section{DISCUSSION}

The sperm agglutination test has been an important immunological assay for antibody against spermatozoa. However, the test has one serious limitation that weakens its reliability. There is no simple, satisfactory method of recognizing non-specific agglutination. In a particular titration, one assumes that the agglutination observed is due to antibody against spermatozoa and not to a non-specific agglutinating factor. This inadequacy is further amplified by the fact that spermatozoa are known to agglutinate under a wide range of circumstances. Head-to-head agglutination of mammalian spermatozoa in normal serum and physiological saline solutions has been reported by a number of workers (Chang, 1947; Henle et al., 1938; Smith, 1949). Chang (1947) also cited that agglutination occurred in egg albumin, plasma fractions, trypsin and tissue extracts. Tail-to-tail non-specific agglutination, in general, occurs much less commonly. However, Smith (1949) found tail agglutination of rabbit spermatozoa in normal human and goat serum. Although Smith never found rabbit spermatozoa to agglutinate through their tails in normal rabbit serum, Edwards (1960) found this tail agglutination in serum from one of his control rabbits. Tail agglutination was reported by Bedford (1965) to occur with immature rabbit spermatozoa in Ringer's solution and with mature rabbit spermatozoa in low electrolyte solutions. The present report adds bacteria to the list of non-antibody sperm agglutinins.

Kibrick's sperm agglutination test (Kibrick, Belding \& Merrill, 1952) which uses a gelatin suspending fluid, provides a splendid medium for growth of bacteria. The apparent ease of chance contamination with sperm-agglutinatingbacteria means that care must be exercised when employing this test to avoid false positive reactions by bacteria. Although it was not the purpose of the present report to investigate the number of species that may agglutinate spermatozoa, there was some suggestion that sperm-agglutinating bacteria may be quite common.

Immunological assays such as the mixed-cell antiglobulin test (Edwards, Ferguson \& Coombs, 1964) or the haemagglutination test have controls available to detect non-specific reactions. Unfortunately these or other assays cannot be used as controls for the sperm agglutination reaction since the antibodies being detected are probably not entirely the same.

The intense agglutination of spermatozoa that occurred with Pseudomonas 
maltophilia raised the speculation that these bacteria might be associated with problems of infertility. Although P. maltophilia is not considered to be a pathogenic bacterium, it has been isolated from animal and human tissues including the human oviduct (Hugh \& Ryschenkow, 1961). Fertility could be affected by the presence of this organism in either the male or female reproductive tract.

Many workers have examined agglutination of spermatozoa by antibody in relation to fertility. In the male, sperm agglutinating autoantibodies have been reported in sterile men (Rümke \& Hellinga, 1959; Nakabayashi, Tyler \& Tyler 1961; Phadke \& Padukone, 1964; Rümke, 1967). Although Phadke \& Padukone (1964) concluded that these sperm agglutinins were not "responsible or indicative of infertility", Rümke \& Hellinga (1959) and Rümke (1967) found a close correlation between the titre of sperm agglutinins in the serum and infertility of the male host.

Sperm agglutinins in the serum of human females have been examined by Franklin \& Dukes (1964) from a group of women with a history of 'unexplained infertility'. When tested against their husbands' semen for sperm agglutinins, a very high percentage were positive. An identical study by Tyler, Tyler \& Denny (1967) failed to confirm this high percentage. This latter group found only a small percentage of positives and concluded that there was only a "tendency towards a correlation between presence of sperm agglutinins and fertility status".

McLaren (1964) produced high levels of mouse sperm agglutinating antibody by iso-immunization. She found a marked decrease in the number of spermatozoa reaching the ampulla of the oviduct in immunized female mice that corresponded to a decrease in the number of fertilized eggs. This clearly suggested that the induced infertility resulted from the inability of the spermatozoa to reach the ova.

It is conceivable that bacterial interference with sperm motility by agglutination, as exemplified by $P$. maltophilia, might be important in some cases of infertility and might even find application in contraception techniques.

\section{ACKNOWLEDGMENTS}

This investigation was supported by a Public Health Service fellowship (No. 5-F2-HD-30, 823-02) from the National Institutes of Child Health and Human Development. I would like to thank Dr Anne McLaren for supervision of the work and criticism of the manuscript. I also thank Dr B. Davies of the Bacteriology Department, University of Edinburgh, and Dr Patricia Carpenter of the Dysentery Reference Laboratory, Central Public Health Laboratory, London, for identifying the organisms and supplying the reference stains.

\section{REFERENCES}

BEDford, J. M. (1965) Non-specific tail-tail agglutination of mammalian spermatozoa. Expl Cell Res. 38,654 .

Chang, M. C. (1947) The effects of serum on spermatozoa. 7. gen. Physiol. 30, 321.

EDWARDs, R. G. (1960) Complement-fixing activity of normal rabbit serum with rabbit spermatozoa and seminal plasma. F. Reprod. Fert. 1, 268. 
Edwards, R. G., Ferguson, L. G. \& Coombs, R. R. A. (1964) Blood group antigens on human spermatozoa. F. Reprod. Fert. 7, 153.

Frankin, R. R. \& Dukes, G. D. (1964) Antispermatozoal antibody and unexplained infertility. Am. 7. Obstet. Gynec. 89, 6.

Henle, W., Henle, G. \& Chambers, L. A. (1938) Studies on the antigenic structure of some mammalian spermatozoa. F. exp. Med. 68, 335.

Hugh, R. \& Ryschenkow, E. (1961) Pseudomonas maltophilia, an Alcaligenes-like species. 7. gen. Microbiol. 26, 123.

Kibrick, S., Belding, D. L. \& Merrill, B. (1952) Methods for the detection of antibodies against mammalian spermatozoa. II. A gelatin agglutination test. Fert. Steril. 3, 430.

McLaren, A. (1964) Immunological control of fertility in female mice. Nature, Lond. 201, 582.

MetchnikofF, M. E. (1900) Recherches sur l'influence de l'organisme sur les toxines. Sur la spermotoxine et l'antispermotoxine. Annls Inst. Pasteur, Paris, 14, I.

Nakabayashi, N. T., Tyler, E. T. \& Tyler, A. (1961) Immunologic aspects of human infertility. Fert. Steril. 12, 544.

Phadkz, A. M. \& Padukone, K. (1964) Presence and significance of autoantibodies against spermatozoa in the blood of men with obstructed vas deferens. F. Reprod. Fert. 7, 163.

Rüмke, P. (1967) Autoantibodies to sperm in man. International Symposium on Immunology of Spermatozoa and Fertilization, Varna, Bulgaria.

Rümke, P. \& Hellinga, G. (1959) Autoantibodies against spermatozoa in sterile man. Am. F. clin. Path. 32, 357.

Sмrth, A. U. (1949) Some antigenic properties of mammalian spermatozoa. Proc. R. Soc. B, 136, 46.

SNELL, G. D. \& Poucher, H. (1943) Relation of number of injections to the titer of sperm iso-agglutinins in mice. Proc. Soc. exp. Biol. Med. 54, 261.

Tyler, A., Tyler, E. T. \& Denny, P. C. (1967) Concepts and experiments in immunoreproduction. Fert. Steril. 18, 153.

Weichardi, W. (1901) Recherches sur l'antispermotoxine. Annls Inst. Pasteur, Paris, 15, 832. 